\title{
Economic impacts of short rotation woody crops in Canada
}

\author{
by Torben Jensen ${ }^{1}$, Tim Keddy², Derek Sidders²
}

\section{ABSTRACT}

Canada is seeking cost-effective means to mitigate greenhouse gas emissions, particularly $\mathrm{CO}_{2}$. One of the promising means is the short rotation woody crops (SRWC) plantation, a silvicultural approach to establishing and managing fast growing plantations on previously cleared lands. This paper utilizes the data set provided by recent harvesting operations at the Ellerslie SRWC Technical Development Site in Edmonton (Alberta) to assess the ability of SRWC using High Yield Afforestation to mitigate GHG emissions and generate more wood fibre and the investment attractiveness to establish future plantations.

Results illustrate that at current trading prices for carbon credits and market prices of woodchips, expected rates of return on investment for SRWC were relatively low, despite a positive net present value ( $\$ 400 /$ ha for 20 year planting cycle without carbon credits). However, estimates from the Ellerslie site indicate that 330 tons of CO2-eq per hectare are captured above and below ground over the 20 year plantation cycle.

However, higher future carbon prices, a well-developed market for buying and selling carbon credits, as well as adapted policy including additional government sponsored programs for carbon credits, could make SRWC more attractive and dramatically change the economics of afforestation in the future.

Keywords: greenhouse gas mitigation; fast-growing tree plantations

\section{RÉSUMÉ}

Le Canada cherche des façons rentables pour atténuer les émissions de gaz à effet de serre, particulièrement celles de $\mathrm{CO}_{2}$. Une des avenues prometteuses repose sur la culture d'essences ligneuse à courtes rotations (short rotation woody crops$S R W C$ ), une approche sylvicole pour la plantation d'essences à croissance rapide et leur aménagement sur d'anciens parterres de coupe. Cet article s'appuie sur les données provenant des récentes opérations de récolte effectuées au centre de développement technique SRWC à Edmonton, en Alberta; il tente de vérifier si la culture d'essences à haut rendement sur de courtes rotations (SRWC) permettait d'atténuer les émissions de GES et de produire plus de fibre ligneuse tout en rehaussant l'intérêt pour l'investissement dans les futures plantations.

Les résultats montrent qu'aux prix où se négocient maintenant les crédits de carbone et avec le prix offert sur le marché pour les copeaux de bois, les taux de retour sur l'investissement pour les SRWC étaient relativement bas en dépit d'une valeur présente nette positive ( $400 \$$ /ha pour des rotations de 20 ans sans crédits carbone). Cependant, les estimations obtenues pour le site d'Ellersie indiquent qu'on pourrait séquestrer 330 tonnes d'équivalent de $\mathrm{CO}^{2}$ par hectare audessus et dans le sol avec des rotations de 20 ans.

Toutefois, des prix plus élevés attendus pour le carbone, un marché bien développé pour l'achat et la vente de crédits carbone et des politiques mieux adaptées incluant des programmes financés par le gouvernement pour les carbone crédits, augmenteraient l'intérêt pour la SRWC et changeraient radicalement la valeur économique des plantations dans l'avenir.

Mots-clés: atténuation des gaz à effet de serre; plantations d'essences ligneuses à croissance rapide

\footnotetext{
${ }^{1}$ Canadian Forest Service, 580 Booth St., Ottawa, Ontario K1A 0E4, Canada email: Torben.jensen@nrcan-rncan.gc.ca

${ }^{2}$ Canadian Wood Fibre Centre, Canadian Forest Service, Natural Resources Canada, 5320-122 ${ }^{\text {nd }}$ Street, Edmonton, AB, T6H 3S5, Canada
} 


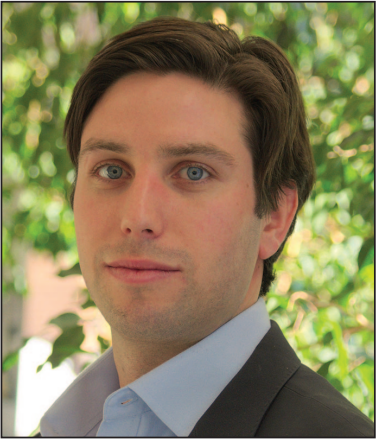

Torben Jensen

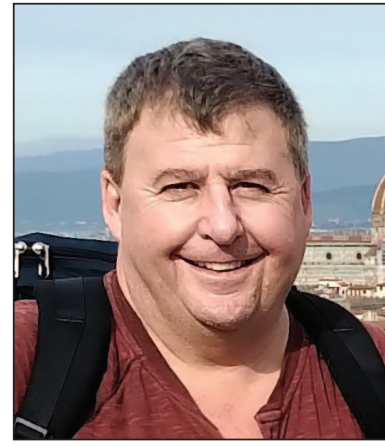

Tim Keddy

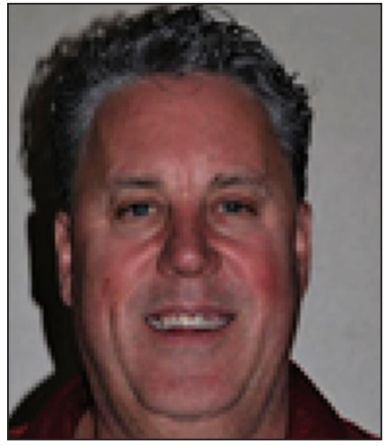

Derek Sidders ronment and Climate Change Canada 2019), and more recently, to achieve a zero green-house gas emissions target by 2050 .

\section{Methods}

Technology developers from Natural Resources Canada's Canadian Forest Service (CFS) sought to explore how short rotation woody crop (SRWC) plantations could serve as potential cash crops for landown-

\section{Introduction}

In 2003, Natural Resources Canada's Canadian Forest Service created a new initiative entitled: Forest 2020: Plantation Demonstration and Assessment. The two-year, \$20-million federal initiative focused on establishing demonstrations of fast-growing tree plantations across Canada with the goal of mitigating greenhouse gas emissions and generating more wood fibre, and exploring investment mechanisms to attract funds to establish plantations in the future. Global climate change is recognised as one of the most critical environmental, social and political challenges facing modern society. Canada is seeking cost-effective means to mitigate greenhouse gas emissions, particularly $\mathrm{CO}_{2}$, which have been linked to global climate change. The carbon sequestration potential of trees allows activities such as afforestation to contribute to Canada's efforts to achieve targets such as those outlined in the Paris Agreement, where Canada committed to reducing its GHG emissions by 30\% below 2005 levels by 2030 (Envi- ers while contributing to climate change mitigation. Short rotation woody crops is a silvicultural approach to establishing and managing fast-growing plantations on previously cleared lands. These crops are established as a means of rapidly producing high yields of fibre over short rotations (three to 20 years). These crops yield eight times more fibre than native yields for use as wood products and for bioenergy. SRWC, such as high yield afforestation (HYA), offer both a way to enhance local fibre availability by growing more consistent and purpose-grown wood fibre, while helping Canada meet its international greenhouse gas (GHG) emission reduction targets because tree growth can capture and store carbon (Fig. 1).

Since 2003, 27000 hectares of SRWC plantations using the high yield afforestation (HYA) method were established across the country by various stakeholders with a portion of these sites established on non-forested lands (afforestation), using a variety of methods proposed by CFS developers

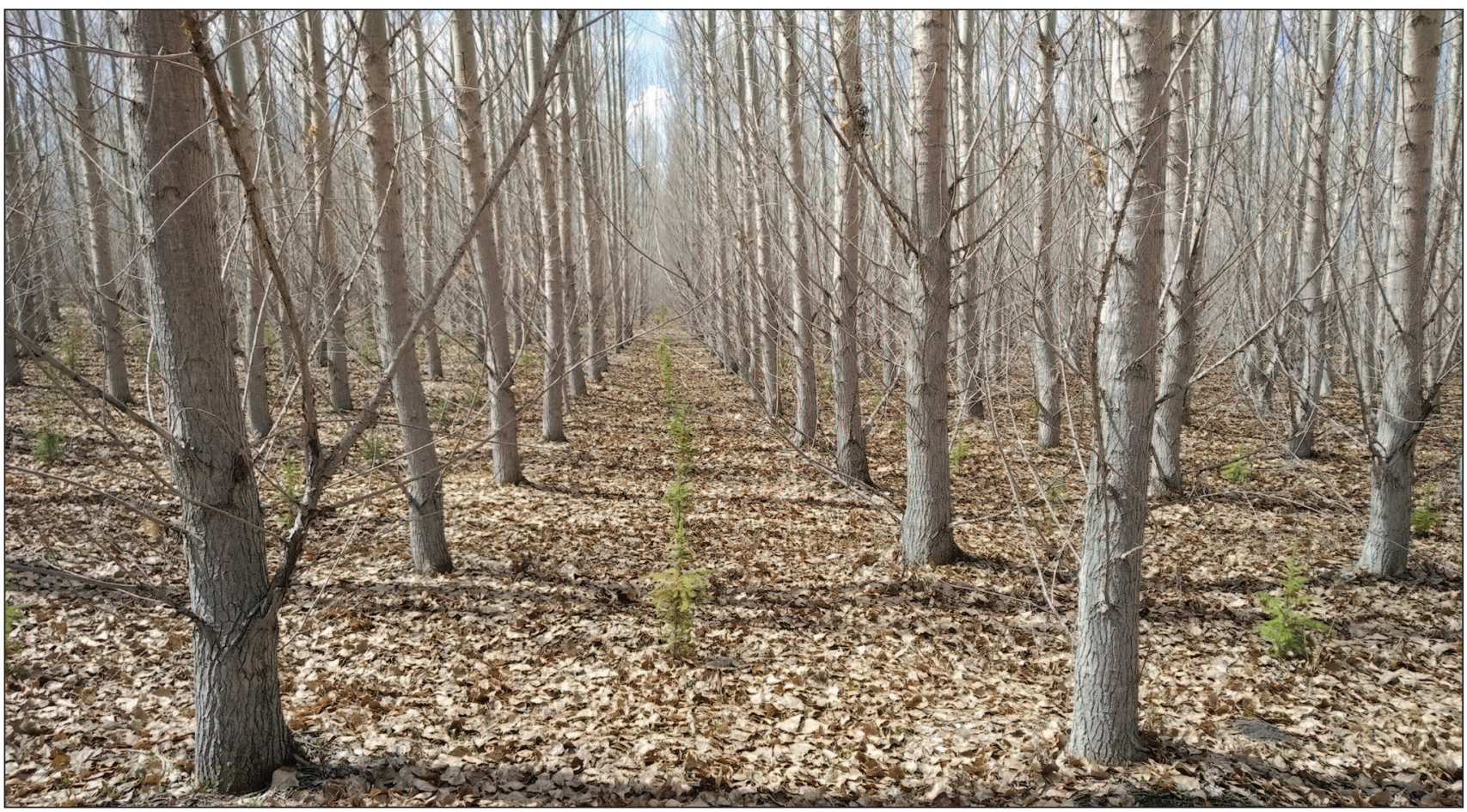

Fig. 1 High-Yield Afforestation plantation at the technical development site in Edmonton 


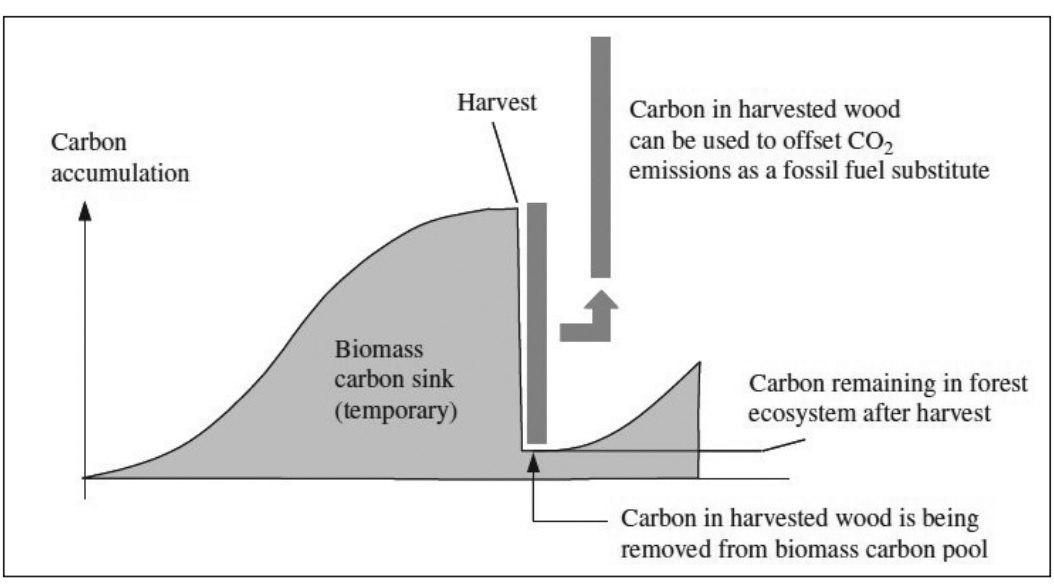

Fig. 2 Afforestation and carbon sequestration over time. Source: Environment and Climate Change Canada (2020)

(Dominy et al. 2010). HYA has demonstrated the greatest economic potential, as the orchard style plantations reduce establishment and harvesting costs and yield the greatest potential volume of fibre per hectare. For HYA, consisting of hybrid poplar or aspen, plantings are typically 1100 to 1600 stems per hectare resembling an orchard style grid layout to achieve high yields (eight times higher than native yields) over short rotations (three to 20 years). This analysis measures the effects of HYA only, therefore all future mention of SRWC refers to the HYA method.

\section{Results}

Economic impact

This economic analysis utilizes data from CFS developers to assess the investment attractiveness of SRWC on current sites. This is done, taking into account such factors as site preparation, growth rates, harvest costs, transportation costs, current market prices and potential carbon prices. CFS developers at the Ellerslie SRWC Technical Development Site in Edmonton have recently completed harvesting operations that presented a unique opportunity to evaluate SRWC from establishment to harvest. This analysis makes use of the complete data set to evaluate the costs and benefits of SRWC and achieved two desired results:

1. Mitigate GHG emissions and generate more wood fibre; and,

2. Investment attractiveness of SRWC to establish future plantations (Fig. 2).

Through a cost-benefit analysis, the results from the Ellerslie site were extrapolated to evaluate the tangible benefits of the 27 thousand hectares of SRWC already planted across the country. For this purpose, it is assumed that: 1) the average growth yields from the Ellerslie site are representative of other sites; 2) the final product is chipped on site before transportation; and, 3 ) cash flows are discounted at 3\% as per Treasury Board specifications. This report builds on the field work conducted by CFS developers at the Ellerslie SRWC Technical Development Site.

\section{Net present value}

When judging long-term investments, it is important to note that a dollar earned today is not worth the same as a dollar earned tomorrow, due to inflation, risk, and the opportunity cost of other potential investments. As such, a good metric to judge the profitability of an investment over time is the net present value (NPV). NPV is the difference between the present value of cash inflows and the present value of cash outflows over a period of time, which provides a method for evaluating and comparing capital projects. In this study, the cash flows (costs and revenues) were discounted with an interest rate of $3 \%^{1}$ and set to a base year $(=0)$. For SRWC, discounting is working against it because the majority of costs occur at the beginning of the project lifecycle, while the revenues are realised at the end of the project lifecycle.

\section{Mitigate GHG emissions}

One of the main drivers for the Forest 2020 program was to develop cost effective means to reduce GHG emissions. As trees are natural carbon sinks, CFS developers were able to estimate the tonnes of $\mathrm{CO}_{2}$ equivalent captured over time from the SRWC plantations. As trees grow, they increase their fibre volume, capturing additional $\mathrm{CO}_{2}$ over time. Estimates from the Ellerslie site indicate that 330 tonnes of $\mathrm{CO}_{2}$ equivalent $\left(\mathrm{CO}_{2}\right.$-eq) per hectare are captured above and below ground over the 20 year plantation cycle, an average of 16.5 tonnes of $\mathrm{CO}_{2}$-eq per year (Fig. 3).

\section{Generating more wood fibre}

Results of the CBA indicate that the Ellerslie site is capable of generating a significant amount of wood fibre from a relatively short growing cycle. CFS developers indicate that over the 20 year growing cycle, yields were 150 oven dried tonnes (ODT) of chips per hectare, where $92 \%$ of chips were suitable for pulp and the remaining $8 \%$ for biomass facilities. At a market price for woodchips of $\$ 110$ per $\mathrm{ODT}^{2}$, total revenues for the harvest were about $\$ 16500$ per hectare. Total costs for site prep, planting, harvesting, processing and transportation were about $\$ 13500$ per hectare, bringing total profits to $\$ 3000$ per hectare (over 20 years, undiscounted).

\section{Investment attractiveness}

Twenty years is a long time for land owners to wait to realise the payout from their investments. When applying the NPV methodology, the business case for SRWC becomes less compelling as site preparation, planting and vegetation management costs all occur within the first five years, with final harvest occurring at year 20. As a result, the NPV over the 20 year planting cycle is $\$ 400$ per hectare. Although a positive NPV indicates that this is a worthwhile investment, without the ability to generate other revenue streams such as selling carbon credits, an NPV of $\$ 400$ per hectare over 20 years offers little incentive to private landowners to pursue SRWC as an investment, given the market value for fibre alone.

\section{Impact of current sites}

Canada currently has 27 thousand hectares SRWC plantations that use the HYA method. Assuming that all sites

\footnotetext{
${ }_{13 \%}$ Discount rate as set by the Treasury board of Canada (2020) ${ }^{2}$ RISI - Western Canadian woodchip prices (2020)
} 


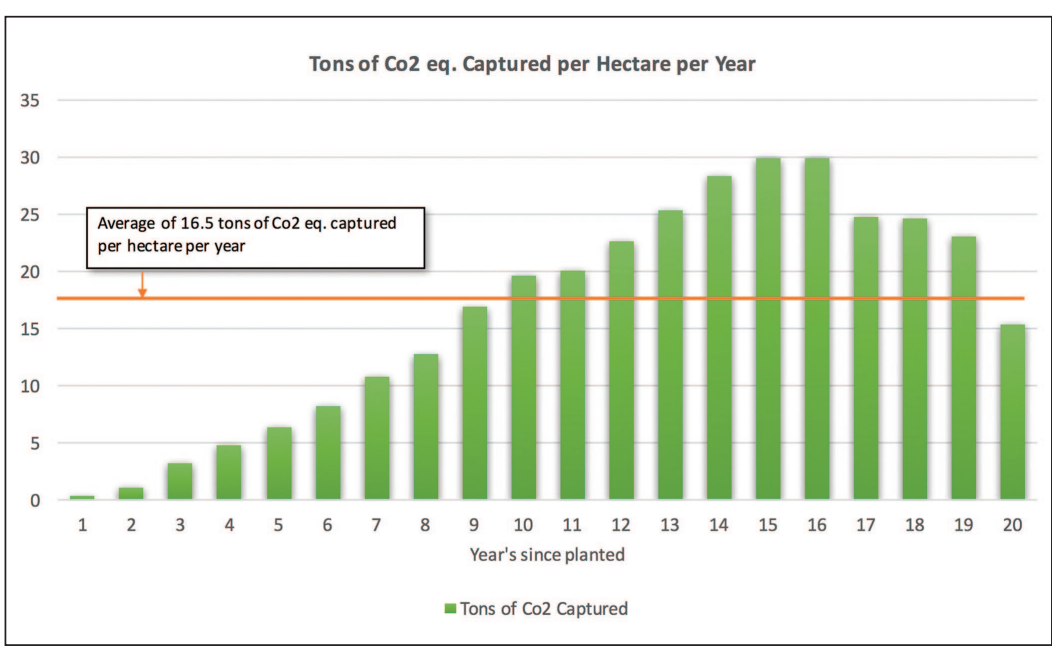

Fig. 3 Carbon sequestration potential of high-yield afforestation over time.
(63 direct, 61 indirect, 42 induced) and total GDP contributions of $\$ 18.8$ million $(\$ 7.4$ million direct and $\$ 6.9$ million indirect).

\section{Conclusion}

Analyses based on modelled data illustrated that at current trading prices for carbon credits and market prices of chips for biomass and pulp and paper manufactures, expected rates of return on investment for afforestation were relatively low. NPV of the 20 -year planting cycle is $\$ 400$ per hectare without carbon credits. However, estimates from the Ellerslie site indicate that 330 tonnes of $\mathrm{CO}_{2}$-eq per hectare are captured above and below ground over the 20-year plantation cycle, an average of 16.5 tonnes of $\mathrm{CO}_{2}$-eq per year. As such, higher future carbon prices and a well-developed market for buying and selling carbon credits, as well as additional government sponsored pro-

adhere to the site preparation and growing guidelines ${ }^{3}$ as outlined by CFS developers, and that they produce similar yields to the Ellerslie site, the following benefits could be realised from a 20-year growing cycle.

These 27000 hectares of SRWC have the potential to produce 200 thousand ODT of chips per year with an estimated market value of $\$ 22$ million. Evaluating all of these sites together yield an NPV of \$11 million over the 20 year growing cycle. Although significant, this must be split amongst all the sites. In addition, the current 27000 hectares capture as much as 450 thousand tonnes of $\mathrm{CO}_{2}$-eq per year, equivalent to $0.1 \%$ of Canada's total GHG emissions for 2017. In 2017, the most recent annual dataset in this report, Canada's greenhouse gas emissions were 716 megatonnes of carbon dioxide equivalent $\left(\mathrm{Mt} \mathrm{CO}_{2}\right.$-eq) (Environment and Climate Change Canada 2020).

To put this into context, Canadian pulp and paper producers consumed a total of 24 million ODT of chips in 2019, an average of 237 thousand ODT per facility ${ }^{4}$. The 187 thousand ODT (92\% of total volume) of chips from the current sites suitable for pulp and paper mills each year is roughly equivalent to the input capacity of an average pulp and paper mill. In addition, a typical Canadian bioenergy facility, consumes 1000 tonnes of ODT chips per year to generate one thermal megawatt (MWth) of energy capacity, equivalent energy to power 105 single detached homes. The 16000 ODT ( $8 \%$ of total volume) of chips from the current sites suitable for bioenergy facilities each year, could provide enough biomass to power 16 bioenergy facilities, producing sufficient energy to power 1680 single detached homes each year.

To further evaluate the potential socioeconomic impacts, an $\mathrm{I} / \mathrm{O}$ model $^{5}$ was used which reports the effect based on multipliers for “Total Forest Operations". This model estimates that an increased output in fibre supply of \$22 million per annum are associated with an additional 166 total jobs

\footnotetext{
${ }^{3}$ Operator's Guide to Operations for the Establishment and Maintenance of Afforestation Plantations - CFS (2009)

${ }^{4}$ Fisher Solve business intelligence system (2020)

${ }^{5}$ Custom Tables Provided by Statistics Canada (2020)
} grams such as Forest 2020, could dramatically change the economics of afforestation in the future.

\section{Discussion}

\section{Developing a market to sell carbon offsets}

In order to realize all the potential benefits of SRWC, it is recommended that Natural Resources Canada and the Canadian Council of Forest Ministers further investigate and revisit the possibility of a national market for selling carbon offsets. Scientific research indicates that SRWC can capture and store carbon at scale. However, a lack of policy uptake impedes landowners' and other forest managers' ability to sell carbon credits to high emitters. This lack of policy uptake and absence of a formal carbon market, such as a national cap and trade system, precludes a potential revenue stream for SRWC, limiting further uptake of this technology on additional sites.

The largest impediments restricting landowners from receiving income from afforestation plantations are seen to be the lack of consistent, country-wide afforestation protocols, and the availability of options for individual landowners and non-industrial stakeholders to realize a monetary benefit from carbon sequestration.

Results from applied afforestation research conducted by the CWFC at the Ellerslie SRWC Technical Development Site in Edmonton, AB shows that merchantable 15-year-old HYA hybrid poplar plantations have resulted in an average site carbon increase from 78 to 166 tonnes per hectare, or $112 \%$ when compared to pre-establishment levels. Approximately $57.58 \%$ of the resulting carbon was harvested and taken off-site, while $42.42 \%$ remained on-site following harvesting operations (Fig. 4).

Afforestation plantations, in an agricultural scenario, would allow for longer cropping rotations and result in increased carbon sequestration sinks or offsets. If a countrywide cap and trade system existed across Canada, landowners would be able to realise a steady rate of return from their plantations every year prior to the final harvest. In 2014, Québec linked its cap and trade system to California's as part of the Western Climate Initiative, thereby creating the largest 


\section{5-Year High Yield Afforestation Site Carbon Breakdown}

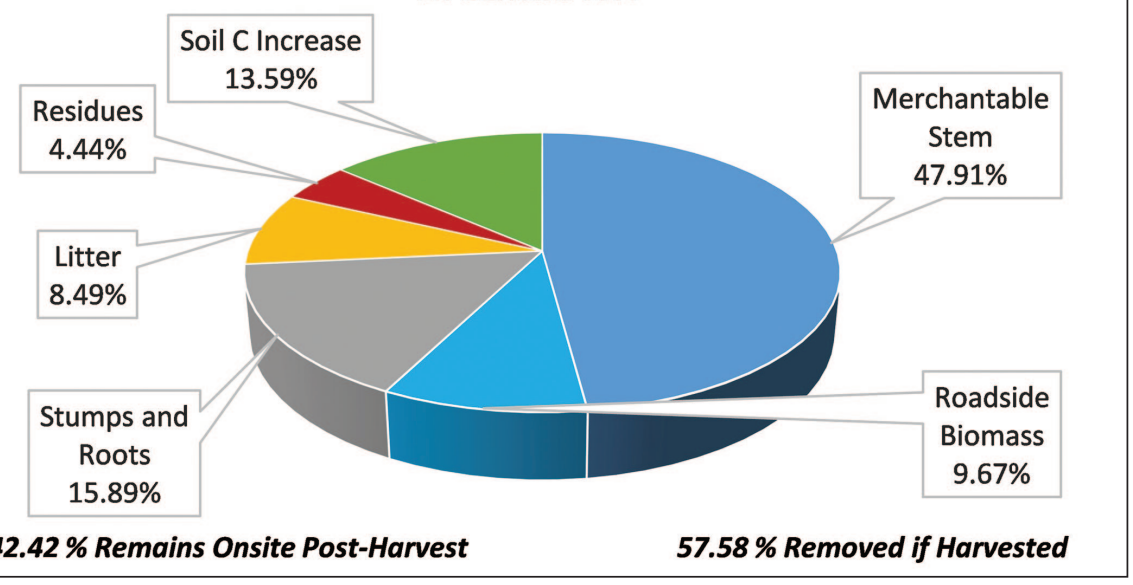

Fig. 4 Breakdown of carbon from high yield afforestation after a 15-year rotation

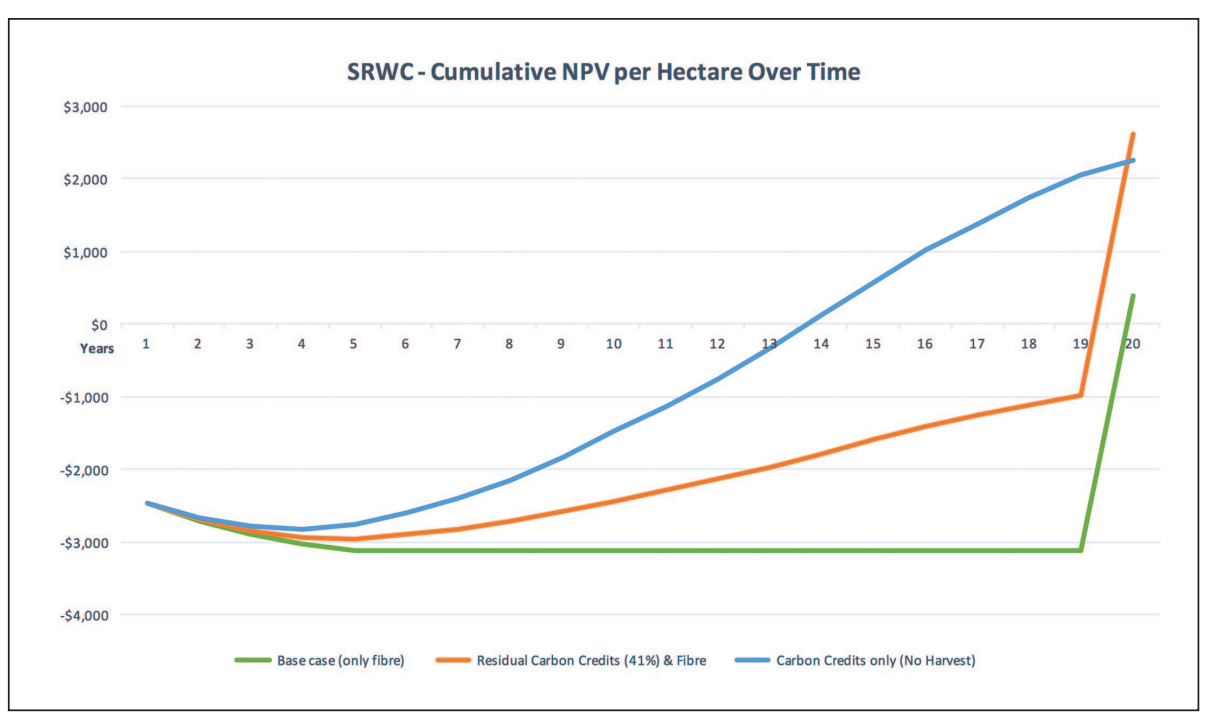

Fig. 5 Comparative analysis of multiple harvest scenarios

carbon market in North America. Ontario was a member until withdrawing in 2019. Based on the February 2020 round of bidding, the rate for carbon credits was set at CAD $\$ 24$ per tonne. This translates into potential profits of $\$ 4700$ per hectare (average of $\$ 230$ per hectare per year) and an NPV of \$2 250 per hectare in carbon credit sales alone for unharvested sites. For landowners that opted to harvest the trees after 20 years, removing $58.7 \%$ of the available carbon from the site, would yield potential profits of $\$ 6300$ per hectare (average of $\$ 320$ per hectare per year) and an NPV of $\$ 2600$ per hectare in carbon credit sales and profits realised from the sale of fibre at harvest (Fig. 5).

A national cap and trade system where private landowners could sell their carbon credits could provide sufficient incentive for land owners to undertake investments in afforestation practices, leading to additional fibre for pulp, paper, and bioenergy facilities, as well as helping Canada meet its targets under the Paris Agreement. In addition, CFS developers are looking at incorporating the planting of toler- ant softwoods in HYA plantations, thereby creating mixedwood afforestation plantations lasting longer than 100 years. This would alleviate the concerns pertaining to permanency while retaining the residual carbon sinks realized by the high-yield afforestation plantations.

\section{Acknowledgements}

This economic analysis is based on long-term research conducted by the CWFC's Technology Development Team in collaboration with soil and climate scientists from the CFS including Dr. Jagtar Bhatti, Dr. Barbara Kishchuk and Dr. Carmela Arevalo, all funded by Federal and Provincial Government Climate Change, Bioenergy, Forest Innovation and Community Development Initiatives, 2002 through 2021. The authors would like to thank Nancy Kingsbury and Susy Domenicano for providing comments on earlier versions of this paper.

\section{References}

S.W.J. Dominy, S.W.J., R. Gilsenan, D.W. McKenney, D.J. Allen, T. Hatton, A. Koven, J. Cary, D. Yemshanov and D. Sidders. 2010. A Retrospective and lessons Learned from Natural Resources Canada's Forest 2020 Afforestation Initiative. For. Chron. 86(3): 339-347. https:// doi.org/10.5558/tfc86339-3

Environment and Climate Change Canada. 2019. Greenhouse gas sources and sinks in Canada. Available from: https://www.canada.ca/en/environment-climate-change/ services/climate-change/greenhouse-gas-emissions/sources-sinksexecutive-summary-2020.html [accessed 18 September 2020].

Environment and Climate Change Canada. 2020. Canadian Environmental Sustainability Indicators: Progress towards Canada's greenhouse gas emissions reduction target [online]. Available from: www.canada.ca/en/environment-climate-change/services/environmental-indicators/progress-towards-canada-greenhouse-gas-emissions-reduction-target.html [accessed 18 September 2020].

\section{Annex - Acronyms and Abbreviations}

CO2-eq Carbon Dioxide Equivalent

ha Hectare

HYA High Yield Afforestation

I/O model Input-Output Model

MWth Thermal Megawatt

NPV Net Present Value

NRCan Natural Resources Canada 